\section{COOKERY AT SOUTH KENSINGTON}

THE most successful department of the International Exhibition this year is undoubtedly that connected with Cookery. Twice a day is a lecture delivered on some practical department of cooking, and at the same time a demonstration is given by a well-trained grcup of female cooks, in a conveniently fitted-up kitchen open to the audience. Thesc lectures are the great attraction of the Exhibition, and many persons anxious to gain admission are turned away for want of space to accommodate them. This shows, at any rate, on the part of the public, an appreciation of the subject and a desire to be instructed as far as possible.

At the same time it is to be lamented that the class of persons who most need instruction in cooking do not attend. The charges of sixpence and a shilling for entrance to hear these lectures and sec the cooking demonstrations must exclude the class of people for whom such instruction is most needed. Although there is a widespread notion that people in England do not know how to cook at all, yet we question very much if the civilised world produces better dinners than are to be found daily on the tables of the wealthy classes of England. They need not to consult economy either in the cost of materials of food or its preparation. For them lectures on cooking are not needed, and even their cooks, who get from fifty to a hundred pounds a year, could hardly be instructed by Mr. Buckmaster and his bevy of cleanly cooks. If anything is wanted by the wealthier classes; it is a more scientific knowledge of the nature of food and the processes by which it is prepared for digestion. This they will not get at South Kensington. Mr. Buckmaster's lectures are not intended as a scientific exposition of the chemical or physical properties of substances used as dict, or of the way in which they affect the palate or act on the body. They consist simply of directions how to prepare dishes, and the cooks in the kitchen follow his directions. There is no doubt that to thousands of people this is of great service. No house. kecper, however low in the scale of society, but must be bencfited by seeing prepared poor man's soup, omelettes, macaroni, and Australian meat, in Mr. Buckmaster's kitchen. At the same time they will learn only how to imitate the methods of cooking they have seen: they will learn no principles. They will hear nothing about the nature of the materials they see cooked, unless it is that hot water and heat act upon them to produce the results they sec. They will see cggs made into an omelette in a frying-pan, but hear nothing with regard to the nature of cggs, their value as an article of diet, and other means or cooking them besides frying.

Another defect we observed in these lectures was the truly British defect of ignoring weights and measures. Mr. Buckmaster's lecture sounded very like the magnification of a receipt out ot an ordinary cookery book. Take a piece of this, a pinch of that; and a handful, a sprig, a few teaspoonfuls, and so on for every ingredient used. We know this is the rule of the kitchen, and any attempt to introduce scales and weights would be flouted with contempt. It is the same with temperature ; water is called "cold," "warm," and "hot," without the slightest allusion to temperature. Surely in leclures like these accuracy ought to be studicd: and when things can be measured and weighed, so good an opportunity of teaching the importance of this should not be lost. It is because of the neglect of these matters in the kitchens of our wealthier classes that they seldom have put on their tables dishes two days alike. Nay, we know more': we tasted some macaroni made by a cook who had been to Mr. Buckmaster's lecture, which was no more like the macaroni made in his kitchen than his was like plum pudding. This arose entirely from the cook not measuring rightly the time of cooking the macaroni and the quantity of the flavouring ingredients.

Now we do not say it is possible to teacli all the science of cookery in one lecture, but we do say that it is possible to speak accurately about the weights of the materials used, the degrecs of hcat to be employed in cooking, and the time that things require to cook.

We throw out these suggestions in the hope of seeing them acted upon. There is no doubt that it would be attended with some difficulty. There is the Italian cook, Mr. Buckmaster's cheff, and the four young female cooks, all not only to be educated, but to be got into the frame of mind to submit. We see also that there is a Cookery Committee, who would, we suppose, have to be consulted ; but these gentlemen would, we are sure, assist in introducing so desirable a system of instruction. Mr. Dc Rivaz is on the Committee, and he is well known for his book on cookery called "Round the Table," as also for his receipts in the Quccu newspaper.

Whether there is any intention on the part of this Committee to extend the lectures, and give a course on cookcry comprising the teaching of the elements of the sciences involved in the facts acted upon in the kitchen, we do not know, but this would be a worthy object and probably would succced, as the public is evidently disposed to listen to the subject. It must, however, be done at once, and done in the International Exhibition. It cannot be done at South Kensington; the experiment has becn tried there and failed. The country gentiemen in the Hutse of Commons do not see their way to voting public money for the instruction of people in London. Whether done in London or the country, such courses of instruction would be a capital way of getting a little scientific knowlcdge into the heads of people edgeways, as it were.

But now we come to the question of opening the present lectures to the poor. These lectures were intended for their instruction and got up in their interest, but they are conspicuous by their absence at these lectures. The whole Exhibition is open to them for a shilling, and when they have screwed this sum out of their hard-earned wages, and paid for a crust of bread and cheese and half-a-pint of beer, they have nothing to spare for learning cookery. Yet we are quite sure the money would be well spent. The persons in the community who suffer most for want of economy in cookery are the very poor. They buy their food in the most expensive way, by buying it in small quantitics, and when they have got it they know less than any class how to cook. They know nothing of the way of making; or of the economy of using soup. They hardly know the difference between warm, hot, and boiling water in cooking food. The fact is, we believe, that half the food of this class is really lost for the want of a knowledge of the proper means of cooking it. To such people these lectures 
should be open at the cost of a penny or twopence each lecturc; and that cach person of this class who attends the Exhibition should have the benefit of the lectures and demonstrations, these should be more frequent, and the theatre larger.

Something may be done before the Exhibition closes; but the cookery question is a permanent one. Cannot something be done to cstablish a School of Cookery, in which teaching such as is now going on at the Intcrnational show can be carried on continuously? IVe can conceive such an institution possible, and even sclf-supporting. The whole of the middle and upper classes are interested in getting good cooks, and the school boards shou'd be urged to allow their elder female pupils to attend the instructions given in such an institution. This would be an immense cconomy to all, for it would save a large portion of that waste which now goes on in evcry houschold, in teaching girls to become the sort of cosks they are.

If girls and women could be sent to such a school with a previous elementary knowledge of chemistry, physiology, and natural philosophy, they woald derive more advan. tage than they would otherwise get from the necessarily short courses in such a school. In short it comes to this, that rearly all the details of practical life are dependent on facts which are comprehended in the various branches of scientific knowledge; and it is only as men and women are taught the nature of these facts that society can progress and man attain the highest possibilities of civilisation.

E. LANKESTER

\section{COX'S POPULAR PSYCHOLOGY}

What am I? A Popular Introduction to Mental Philosophy and Psychology. Vol. I. The Mechanism of Man. IBy Edward William Cox, Serjeant-at-law. (Longmans and Co.)

No doubt many of the Serjeant's friends will read his popular introduction to the study of psychology, and think it very profound, and many of them, especially his lady friends, charmed with the vague denunciation of "Scientists" and materialists, the religious element, the quackery of science, and the scraps of poetry, will be able to tell him in all sincerity that they think it "a vcry nice book." But from those whose opinion is worth the paper it is written on, Mr. Cox has nothing to hope. The first sentence of the preface declares that "The study of psychology has not kept pace with the progress of the physical sciences." The truth of this statement must be painfully brought home to every real student of psychology, by the fact that a man possessing the intelligence and general culture of Mr. Cox could write such a book, and that educated people will be found to read it. We can agree with the author that there is at the present time ruom for a work presenting the leading truths of mental science in, if possible, a popular shape. But surely one qualification of the writer who would make such a book for the bencfit of the "many persons who desire to obtain s me knowledge of psychology, but who are deterred from its study by the ponderous volumes of abstruse argument ... intelligible only to the far advanced plilosopher," must be, that he is himself up with the best science of the day, that he has made himself acquainted with "the ponderous volumes of abstruse argument." Unfortunately Mr. Cox docs not appear to have taken this view of the matter. In setting himself to produce an "outline of the science of psychology written in plain language," he has, in plain language, attempted work for which he is no more qualified than an ordinary farm labourer is qualified to translate Homer into the vernacular of his native village.

Like books of its class the volume before us is rich in curious absurdities of presumption. For instance, scientific men are very severely taken to task for their lamentable want of scientific method; and there is no end to the tirade against materialists, metaphysicians, and mental philosophers. Who these greatest of sinners are, we cannot tell; for Mr. Cox prudently refrains from mentioning names. Nor are we told very precisely what are the particularly damnable heresies with which they have poisoned the public mind; indeed, it would appsar that mindful of the good old proverb that one cannot touch tar without bcing defiled, Mr. Cox has been careful to keep his own mind at an angry distance from all their evil thinking. It may however anuse some of our readers to know what, according to $\mathrm{Mr}$. Cox, is not materialism, while it will enable all to estimate the claim of the writer to rank as a psycholorist. This is spiritualism: "Rightly, then to conceive of spirit, the first step is clearly" to comprehend that it is not, and cannot be, immaterial -but only that it is composed of very refined matterso refined that it is imperceptible to our bodily senses, which are adapted only to perceive certain forms of matter that affect ourselves." "The soul, therefore, being composed of molecules infinitely finer than the molecules of the body-as fine possibly as those of the comet, could, with the utmost ease, permeate the body, infusing itself among all the atoms of which the body is built, and thus occupy the whole frame; "and as a consequence "the shape of the soul must be the shape of the body." The soul here spoken of is not "the mind " nor the "life," but the proprietor of the body, the mind, and the life. As Mr. Cox's "inquiry is designed to be purely scientific," and is "addressed mainly to those who reject the authority of the theologian," we must give one specimen of the scientific arguments, in support of the existence of this entity, which scientists in their stupidity have hitherto failed to appreciate. Here is the best one :- "Does any sane man ever talk or write of his mind or his life as 'Me?' Does he not always say ' my mind,' 'your mind, 'my life,' 'your life,'-that is to say 'the mind, the life, -that belongs to me,' 'the life-the mind-that belongs to you," We hope the learned serjeant does better than this when he has a concrete mortal for a client. Without going farther a-field for an answer it must be sufficient to remind him that we not only say "my mind," and " your mind," but also " my soul," and "your soul," "myself," and "yourself." Who, or what is the " $M f c$," which according to the profound word-argument must exist as the proprietor of the sout and the sclf? This very refined existence has not yet got a name; but perhaps Mr. Cox, now his attention has been called to it, will be able to tell us in his second volume (which already promises to be much more interesting than the one before us) what sort of matter it is made of, its shape, and its dwelling place. 